\title{
COMENTARIOS A LA SENTENCIA DEL TRIBUNAL DE JUSTICIA DE LA UNIÓN EUROPEA DE 21 DE DICIEMBRE DE 2016

\author{
COMMENTS ON THE SENTENCE OF THE COURT OF JUSTICE \\ OF THE EUROPEAN UNION OF 21 DECEMBER 2016
}

\author{
JAVIER GÓMEZ GÁlLIGO \\ Director General de los Registros y del Notariado
}

Recibido: 13.01.2017 / Aceptado: 15.01.2017

DOI: https://doi.org/10.20318/cdt.2017.3631

\begin{abstract}
Resumen: La finalidad de este trabajo es ofrecer un análisis breve, claro y riguroso del tratamiento que las cláusulas suelo han recibido en la sentencia del Tribunal de Justicia de la Unión Europea, en su sentencia de 21 de Diciembre de 2016, asuntos C-154/15, C-307/15 y C-308/15. Éste ha sido un caso polémico que ha tenido una gran repercusión en la opinión pública española.

Palabras clave: cláusulas suelo, nulidad, retroactividad, Derecho de la UE, efectos ex tunc, protección de consumidores y cláusulas generales de la contratación.
\end{abstract}

Abstract: The purpose of this paper is to provide a brief, clear and rigorous analysis of the treatment that the floor clauses have received in the judgment of the Court of Justice of the European of 21 December 2016, Cases C-154/15, C-307/15 and C-308/15. This has been a controversial case that has had a great impact in the Spanish public opinion.

Keywords: floor clauses, nullity, retroactivity, EU Law, ex tunc effects, consumers protection, general contracting clauses.

Sumario: I. Consideraciones preliminares. II. Las cláusulas suelo. III. Cláusula cero. IV. Efectos ex tunc de la nulidad. V. Prescripción de la acción. VI. El mecanismo especial de arreglo de diferencias.

\section{Consideraciones preliminares}

1. El Tribunal de Justicia de la Unión Europea, en su sentencia de 21 de Diciembre de 2016, asuntos C-154/15, C-307/15 y C-308/15'1 , ha fallado que la interpretación del artículo 6, apartado 1, de la Directiva 93/13/CEE del Consejo, de 5 de abril de 1993, sobre cláusulas abusivas en los contratos celebrados con consumidores, se opone a una jurisprudencia nacional que limita en el tiempo los efectos restitutorios vinculados a la declaración del carácter abusivo, en el sentido del artículo 3, apartado 1, de dicha Directiva, de una cláusula contenida en un contrato celebrado con un consumidor por un profesio-

\footnotetext{
1 STJUE 21 de diciembre de 2016, Francisco Gutiérrez Naranjo contra Cajasur Banco SAU, Ana María Palacios Martínez contra Banco Bilbao Vizcaya Argentaria SA (BBVA), Banco Popular Español SA contra Emilio Irles López y Teresa Torres Andreu, asuntos acumulados C-154/15, C-307/15 y C-308/15, ECLI:EU:C:2016:980. Esta sentencia del TJUE es consecuencia de las cuestiones prejudiciales planteadas con arreglo al artículo 267 TFUE, por el Juzgado de lo Mercantil n. ${ }^{\circ} 1$ de Granada.
} 
nal, circunscribiendo tales efectos restitutorios exclusivamente a las cantidades pagadas indebidamente en aplicación de tal cláusula con posterioridad al pronunciamiento de la resolución judicial mediante la que se declaró el carácter abusivo de la cláusula en cuestión.

En definitiva considera no ajustada al Derecho de la Unión Europea la jurisprudencia del Tribunal Supremo español, por la que se establece el carácter no retroactivo de la doctrina contenida en su Sentencia n. ${ }^{\circ}$ 241/2013, de 9 de mayo de 2013 en la que, el Tribunal Supremo, tras constatar el carácter abusivo de las cláusulas que establecían un umbral mínimo por debajo del cual no podía situarse el tipo de interés variable (en lo sucesivo, «cláusulas suelo»), cláusulas contenidas en las condiciones generales de los contratos de préstamo hipotecario celebrados con los consumidores, declaró la nulidad de tales cláusulas.

\section{Las cláusulas suelo}

2. El Tribunal Supremo español había declarado en esta sentencia de 9 de Mayo de 2013 la nulidad por abusivas de las cláusulas suelo contenidas en los préstamos hipotecarios a interés variable, en las que se fijaba un porcentaje mínimo de evolución², cuando la entidad financiera, como predisponente de la condición general, no hubiera informado suficientemente al consumidor de los riesgos asumidos.

3. Debe recordarse que estamos en el ámbito de condiciones generales de la contratación, en la medida que son cláusulas predispuestas que impone una de las partes (la entidad financiera) al consumidor, con independencia de la autoría material de las mismas. Y aunque pueda entenderse que los intereses, tanto ordinarios como de demora, forman parte del contenido principal del contrato, hay que recordar que en nuestro Derecho no está excluido que también cuando éste sea regulado a través de clausulado de condiciones generales, le sean aplicable la normativa protectora del consumidor en esta clase de contratación. Y ello no sólo porque la Ley de condiciones generales de la contratación no excluya expresamente de su ámbito la definición del objeto principal del contrato, sino sobre todo porque la propia Directiva 93/13/CE somete a los mismos controles de abusividad a las cláusulas que no hayan sido transparentes ${ }^{3}$.

4. Las cláusulas suelo en los intereses variables no es que en sí mismas sean abusivas, sino que pueden llegar a serlo si no se ha explicado al consumidor suficientemente su transcendencia y significado, esto es, los riesgos de suscribir un contrato donde se ha incorporado una cláusula de esta naturaleza. Dicho de otra forma, si la cláusula suelo está suficientemente explicada, a través de ejemplos en escenarios diversos de evolución de los tipos de interés, la cláusula suelo será plenamente válida, máxime si se fija paralelamente una cláusula techo de evolución de los tipos de interés (límite mínimo y máximo de evolución).

Se habla así tanto en la doctrina como en la jurisprudencia, de un doble control de incorporación: el consumidor no sólo debe entender gramaticalmente lo que firma sino que además debe comprender los riesgos derivados de la cláusula firmada. Esto explica que la jurisprudencia del TJUE haya declarado nulas las condiciones generales que no sean entendibles por un consumidor medio, normalmente informado y razonablemente atento y perspicaz en la terminología del Alto Tribunal europeo.

\footnotetext{
${ }^{2}$ La cláusula de interés variable consiste en pactar un tipo de interés inicial nominal anual del X\% por cien, que estará vigente hasta el día que se cumplan Y meses de la fecha de formalización. Se pacta la periodicidad de revisión del tipo de interés y un diferencial de $\mathrm{Z}$ puntos sobre el tipo de referencia (un tipo de referencia oficial variable como el EURIBOR o el IRPH, publicados en BOE de conformidad con la Circular 8/90 del Banco de España). No obstante lo anterior, se establece que en las revisiones el tipo de interés nominal aplicable no será superior al X \% (en el caso 15,000 por cien anual), ni inferior al X' \% (en el caso el 3,250 por cien nominal).

3 El artículo 4.2 de la Directiva 93/13/CE establece que la apreciación del carácter abusivo de las cláusulas no se referirá a la definición del objeto principal del contrato ni a la adecuación entre precio y retribución, por una parte, ni a los servicios o bienes que hayan de proporcionarse como contrapartida, por otra, siempre que dichas cláusulas se redacten de manera clara y comprensible. Lo que a sensu contario significa que cuando no haya una explicación clara y comprensible de las condiciones generales atinentes al objeto principal, estarán sujetas a la posibilidad de impugnación por abusividad.
} 
5. El clausulado de los préstamos y créditos hipotecarios debe ser interpretado conforme al art. 4.2 y 5 de la Directiva 93/13/CEE según ha declarado el TJUE4. En la sentencia de 23 de abril de 2015 recuerda que, según su propia jurisprudencia interpretativa de la Directiva sobre las cláusulas abusivas, la apreciación del carácter abusivo de las cláusulas no se refiere a la definición del objeto principal del contrato ni a la adecuación entre precio y retribución, siempre que se cumplan con los requisitos de transparencias.

Por tanto, la cláusula debe ser clara y transparente, es decir, estar redactada de modo comprensible para el consumidor. Para considerar que las cláusulas están redactadas de manera clara y comprensible no sólo hay que atender al "plano gramatical", sino también a que expongan "de manera transparente el funcionamiento concreto del mecanismo". Y es aquí donde asegura que "hay que tener en cuenta el entramado contractual en el que se inserten, de manera que el consumidor de que se trate esté en condiciones de valorar, basándose en criterios precisos e inteligibles, las consecuencias económicas que para él se deriven de tales cláusulas". De no ser así, añade, "el tribunal nacional podrá apreciar el posible carácter abusivo de la cláusula en cuestión".

6. Esto es predicable de las cláusulas suelo de tipos de interés de los préstamos hipotecarios a pesar de estar formalizados ante notario, esto es, en escritura pública. Y por eso no basta con que al consumidor se le lea la escritura ni que la entienda, sino que tiene que comprender los riesgos que para su patrimonio puede llegar a tener. Podemos llegar a concluir (aunque esto no lo haya dicho -aún- el TJUE) que ni siquiera la firma manuscrita del propio consumidor, afirmando estar informado, exigida por la Ley 1/2013 para la protección de los deudores hipotecarios sea suficiente a este efecto. ${ }^{7}$ Se re-

4 STJUE 21 de marzo de 2013; STJUE de 30 de abril de 2014 y la STJUE de 26 febrero de 2015.

5 Eso es precisamente lo que ocurría en el caso en litigio, que afectaba al objeto principal y no había sido suficientemente informado el consumidor al tratarse de un contrato de seguro, eso sí, ligado a un contrato de préstamo para la adquisición de un bien inmueble, con el fin de asegurar un hipotético impago de las mensualidades por parte del consumidor en caso de encontrarse en situación de incapacidad total para trabajar.

6 STJUE 26 de febrero de 2015, Matei, C-143/13, ECLI:EU:C:2015:127, se refiere igualmente al deber de transparencia real en los siguientes términos:

"73. A este respecto, debe recordarse que la exigencia de transparencia de las cláusulas contractuales establecida en los artículos 4, apartado 2, y 5 de la Directiva 93/13 — los cuales tienen, por lo demás, un alcance idéntico- no puede reducirse sólo al carácter comprensible de aquéllas en un plano formal y gramatical (véase, en este sentido, la STJUE 30 de abril de 2014 , Kásler y Káslerné Rábai, C-26/13, EU:C:2014:282, apartados 69 y 71).

74. De los artículos 3 y 5 de la Directiva 93/13 y de los puntos 1, letras j) y 1), y 2, letras b) y d), del anexo de la misma Directiva resulta, en particular, que para satisfacer la exigencia de transparencia reviste una importancia capital la cuestión de si el contrato de préstamo expone de manera transparente los motivos y las particularidades del mecanismo de modificación del tipo del interés, así como la relación entre dicha cláusula y otras cláusulas relativas a la retribución del prestamista, de forma que un consumidor informado pueda prever, sobre la base de criterios precisos y comprensibles, las consecuencias económicas que para él se derivan (véase, en este sentido, la STJUE 30 de abril de 2014, Kásler y Káslerné Rábai, C-26/13, EU:C:2014:282, apartado 73).

75. Tal cuestión debe ser examinada por el tribunal remitente a la vista de todos los elementos de hecho pertinentes, entre los que se encuentran la publicidad y la información proporcionadas por el prestamista en el marco de la negociación de un contrato de préstamo, y teniendo en cuenta el nivel de atención que puede esperarse de un consumidor medio normalmente informado y razonablemente atento y perspicaz (véase, en este sentido, la STJUE 30 de abril de 2014, Kásler y Káslerné Rábai, C-26/13, EU:C:2014:282, apartado 74)"'.

En el mismo sentido la STJUE 30 de abril de 2014, Kásler y Káslerné Rábai ,C-26/13, EU:C:2014:282, citada en la STS de 8 de septiembre de 2014, declara que: "la exigencia de que una cláusula contractual debe redactarse de manera clara y comprensible se ha de entender como una obligación no sólo de que la cláusula considerada sea clara y comprensible gramaticalmente para el consumidor, sino también de que el contrato exponga de manera transparente el funcionamiento concreto del mecanismo de conversión de la divisa extranjera al que se refiere la cláusula referida, así como la relación entre ese mecanismo y el prescrito por otras cláusulas relativas a la entrega del préstamo, de forma que ese consumidor pueda evaluar, basándose en criterios precisos y comprensibles, las consecuencias económicas derivadas a su cargo".

7 El artículo 6 de la Ley 1/2013, de 14 de Mayo de medidas para reforzar la protección de los deudores hipotecarios, exige que en la escritura de préstamo hipotecario se incluya, junto a la firma del cliente, una expresión manuscrita, por la que el prestatario manifieste que ha sido adecuadamente advertido de los posibles riesgos derivados del contrato. Los contratos que requerirán la citada expresión manuscrita serán aquellos que se suscriban con un prestatario, persona física, en los que la hipoteca recaiga sobre una vivienda o cuya finalidad sea adquirir o conservar derechos de propiedad sobre terrenos o edificios construidos o por construir, en los que concurra alguna de las siguientes circunstancias: a) que se estipulen limitaciones a la variabilidad del tipo de interés, del tipo de las cláusulas suelo y techo, en los cuales el límite de variabilidad a la baja sea infe- 
quiere comprensión gramatical de la cláusula, y explicación de los riesgos, de manera que ni la firma manuscrita ni la lectura por el notario de la cláusula puede sustituir ese entendimiento de los riesgos que se están asumiendo.

\section{Cláusula cero}

7. Este mismo debate sobre el control de inclusión en el contrato y de transparencia de la cláusula suelo es extrapolable a la denominada "cláusula cero", por virtud de la cual se establece que el préstamo no devengará intereses negativos. Desde un punto de vista conceptual se defiende que es de esencia de los contratos de préstamo que exista un interés en favor del prestamista, pues lo contrario desnaturalizaría el contrato, por lo que no debería plantear mayores problemas de inclusión una cláusula de este tipo. Sin embargo, la doctrina de la Dirección General de los Registros y del Notariado, es la de tratar esta cláusula como las demás cláusulas suelo y por tanto exigir del doble control de incorporación y transparencia, y por ende la firma manuscrita (véase por todas Resolución DGRN de 10 de Noviembre de 2016 que se planteó un caso de cláusula suelo ${ }^{8}$ ).

La DGRN aunque reconoce que el préstamo es por esencia retribuido y que en su cómputo global no puede el prestamista terminar pagando al prestatario, no obstante admite que en el cálculo de los intereses en los períodos contractuales pueden atravesarse coyunturas de intereses negativos ${ }^{9}$.

rior al límite de variabilidad al alza; b) que lleven asociada la contratación de un instrumento de cobertura del riesgo de tipo de interés, o bien; c) que se concedan en una o varias divisas.

8 La cuestión que se planteaba en esta resolución consiste en la determinación de si en los préstamos hipotecarios a interés variable en que se pacte que la parte deudora nunca podrá beneficiarse de descensos a intereses negativos, es decir, que no podrá recibir importe alguno como en tales supuestos, es precisa la confección de la expresión manuscrita por parte del deudor de comprender los riesgos que asume en presencia de dicha cláusula, a que se refiere el artículo 6 de la Ley 1/2013 de 14 de mayo, de medidas para reforzar la protección a los deudores hipotecarios, reestructuración de deuda y alquiler social, siempre que se den, como ocurre en el presente caso, los presupuestos de aplicación de la misma. El notario recurrente alega en favor de la no necesidad de la expresión manuscrita en este caso, que el préstamo por naturaleza puede ser gratuito, si no devenga intereses, $\mathrm{u}$ oneroso, si los devenga a favor del prestamista, pero nunca puede devengar intereses a favor del prestatario. Las razones que exponen son, en primer lugar, que el interés por definición es la remuneración del acreedor y, en segundo lugar, que en caso de devengarse en favor del prestatario se estaría alterando la naturaleza jurídica del contrato que dejaría de ser un préstamo mutuo para convertirse en otro tipo de contrato. Además, argumenta en extenso que el pacto del sistema de amortización francés, cuya fórmula consta en la escritura, implica que la cuota de amortización, en cada período de interés, variará atendiendo a cuál sea el tipo de interés aplicable en cada uno de ellos; pero que cuando el tipo de interés constituye un valor negativo, la consecuencia financiera de la aplicación de la fórmula matemática será igual a cuando el préstamo no devenga intereses y, en consecuencia, durante ese período sólo se restituye capital. Por último, afirma el recurrente que una cláusula como la discutida que lo que señala es que en ningún caso podrán devengarse intereses a favor del deudor, no constituye una cláusula contractual de suelo del cero por ciento sino una cláusula de tipo legal o aclaratoria de una condición esencial del contrato de préstamo formalizado de común acuerdo entre ambas partes, que señala que el préstamo nunca devengará intereses a favor del prestatario, pero porque así deriva naturalmente de la Ley y del sistema de amortización francés elegido, es decir, sin que se pacte expresamente un tipo fijo mínimo

9 La DGRN señala que el artículo 6 Ley 1/2013- dispone lo siguiente: «1. En la contratación de préstamos hipotecarios a los que se refiere el apartado siguiente se exigirá que la escritura pública incluya, junto a la firma del cliente, una expresión manuscrita, en los términos que determine el Banco de España, por la que el prestatario manifieste que ha sido adecuadamente advertido de los posibles riesgos derivados del contrato. 2. Los contratos que requerirán la citada expresión manuscrita serán aquellos que se suscriban con un prestatario, persona física, en los que la hipoteca recaiga sobre una vivienda o cuya finalidad sea adquirir o conservar derechos de propiedad sobre terrenos o edificios construidos o por construir, en los que concurra alguna de las siguientes circunstancias: a) que se estipulen limitaciones a la variabilidad del tipo de interés, del tipo de las cláusulas suelo y techo, en los cuales el límite de variabilidad a la baja sea inferior al límite de variabilidad al alza; b) que lleven asociada la contratación de un instrumento de cobertura del riesgo de tipo de interés, o bien; c) que se concedan en una o varias divisas». Por su parte, el Banco de España, en el Anexo 9 de la guía de acceso al préstamo hipotecario de julio de 2013, ya ha determinado los términos de tal expresión al fijar como modelo la siguiente fórmula ritual: «...he sido advertido por la entidad prestamista y por el notario actuante, cada uno dentro de su ámbito de actuación, de los posibles riesgos del contrato y, en particular, de que... el tipo de interés de mi préstamo, a pesar de ser variable, nunca se beneficiará de descensos del tipo de interés de referencia por debajo del [límite mínimo del tipo de interés variable limitado]». Al interpretar esta norma debe tenerse en cuenta, como reiteradamente ha puesto de manifiesto este Centro Directivo, que se ubica en el Capítulo II de la citada Ley 1/2013, de 14 de mayo, bajo la rúbrica del «fortalecimiento de la protección del deudor hipotecario en la comercialización de los préstamos hipotecarios», artículo que como expresa el Preámbulo de la Ley, introduce mejoras en el mercado hipotecario que se adoptan «como consecuencia de la Sentencia del Tribunal de Justicia de la Unión Europea de 14 de marzo de 2013, dictada en el asunto por el que se resuelve la cuestión prejudicial planteada por el Juzgado de lo Mercantil número 3 de Barce- 
lona respecto a la interpretación de la Directiva 93/13/CEE del Consejo, de 5 de abril de 1993». Se trata de una declaración de indudable valor interpretativo que, como señala la Resolución de este Centro Directivo de 12 de marzo de 2015, debe ponerse en relación con la doctrina sentada por el Tribunal de Justicia de la Unión Europea en la citada Sentencia de 14 de marzo de 2013, y con la propia jurisprudencia sentada por nuestro Tribunal Supremo respecto de las normas de nuestro Derecho interno a través de las que se ha traspuesto en nuestro ordenamiento la citada Directiva 93/13/CEE del Consejo, de 5 de abril de 1993 (especialmente la relevante doctrina sentada por la Sentencia de la Sala Primera del Tribunal Supremo número 241/2013, de 9 de mayo), de la que, a su vez, se ha hecho eco la doctrina de este Centro Directivo (vid. las Resoluciones citadas en los «Vistos» de la presente). Una cuestión semejante referida al marco de aplicación del citado artículo 6 de la Ley 1/2013 y los supuestos en que se hace necesario exigir la denominada expresión manuscrita del prestatario, ya fue abordada por este Centro Directivo en la citada Resolución de 12 de marzo de 2015, distinguiendo los distintos ámbitos del control de inclusión, de transparencia y de abusividad de las cláusulas de los préstamos hipotecarios, Resolución a la que se remite la presente y cuya doctrina se resume en los números siguientes, siguiendo el criterio ya recogido en las Resoluciones de 8 y 27 de octubre y 10 de diciembre de 2015 y 15 de julio de 2016. 4. Como puso de relieve esta Dirección General en Resolución de 5 de febrero de 2014, la valoración de las denominadas «cláusulas suelo» se incardina en el ámbito del control de inclusión y de transparencia de los contratos con condiciones generales de la contratación, pues se trata de un control previo al del contenido o abusividad, cuyo análisis en relación con las cláusulas de los contratos de préstamos hipotecarios relativos al objeto principal del contrato, y en particular en relación con las cláusulas de interés variable y las relativas a su composición o determinación, o las cláusulas a ellas asociadas (como en el caso de los contratos o cláusulas de cobertura del riesgo de los intereses variables) ha sido abordada en profundidad por nuestro Tribunal Supremo, Sala Primera, en las Sentencias número 241/2013, de 9 de mayo, y otras posteriores como la número 464/2014, de 8 de septiembre, y la más reciente, Pleno de la Sala Civil, número 139/2015, de 25 de marzo. Partiendo de que las cláusulas que disciplinan contractualmente los intereses variables y las determinaciones accesorias que influyen en su fijación o variación, incluyendo cualquier elemento de coste financiero que vaya asociado al mismo, deben entenderse incluidos en el concepto de «objeto principal del contrato» en el sentido que da a tal expresión la citada Sentencia número 241/2013, de 9 de mayo de la misma («forman parte inescindible del precio que debe pagar el prestatario»), en cuanto resulta relevante en la resolución del presente expediente, interesa subrayar los siguientes pronunciamientos de la primera de las citadas Sentencias: a) como regla general no cabe el control de equilibrio prestacional de estas cláusulas, porque el control de contenido que puede llevarse a cabo en orden al posible carácter abusivo de la cláusula, no se extiende al del equilibrio de las «contraprestaciones» que se identifica con el objeto principal del contrato, de tal forma que no cabe un control del precio, y b) el hecho de que una condición general defina el objeto principal de un contrato y que, como regla, no pueda examinarse la abusividad de su contenido, no supone que el sistema no las someta al doble control de inclusión y transparencia. Cuestión distinta, por tanto, a la del control de contenido o abusividad es la relativa a la transparencia de las cláusulas contractuales. Sobre tal extremo el registrador, como señala la Resolución de esta Dirección General de 13 de septiembre de 2013, no sólo puede sino que debe comprobar si han sido cumplidos los requisitos de información establecidos en la normativa vigente, pues se trata de un criterio objetivo de valoración de dicha transparencia. En este sentido, la reiterada Sentencia del Tribunal Supremo de 9 de mayo de 2013, reconociendo que corresponde a la iniciativa empresarial fijar el interés al que presta el dinero y diseñar la oferta comercial dentro de los límites fijados por el legislador, añade que «también le corresponde comunicar de forma clara, comprensible y destacada la oferta», a lo que añade la citada Sentencia que «el artículo 4-2 de la Directiva 93/13/ CEE dispone que "La apreciación del carácter abusivo de las cláusulas no se referirá a la definición del objeto principal del contrato (...) siempre que dichas cláusulas se redacten de manera clara y comprensible", precepto del que extrae a contrario sensu que "las cláusulas referidas a la definición del objeto principal del contrato se someten a control de abusividad si no están redactadas de manera clara y comprensible"». Esta obligación de claridad y transparencia se controla a través de un doble filtro. El primero es aplicable a todo contrato con condiciones generales de la contratación, con independencia de que en el mismo intervenga o no un consumidor, a través del llamado control de incorporación o inclusión de la cláusula al contrato (vid. artículo 7 de la Ley sobre condiciones generales de la contratación). El segundo filtro, limitado, según doctrina mayoritaria, al caso de los contratos con consumidores, se articula a través del control de transparencia, en relación con el cual la Sentencia del Tribunal Supremo de 9 de mayo de 2013 es elocuente al afirmar que «el artículo 80.1 TRLCU dispone que "en los contratos con consumidores y usuarios que utilicen cláusulas no negociadas individualmente [...], aquéllas deberán cumplir los siguientes requisitos: a) Concreción, claridad y sencillez en la redacción, con posibilidad de comprensión directa [...]; b) Accesibilidad y legibilidad, de forma que permita al consumidor y usuario el conocimiento previo a la celebración del contrato sobre su existencia y contenido", lo que permite concluir que el control de transparencia "cuando se proyecta sobre los elementos esenciales del contrato, tiene por objeto que el adherente conozca o pueda conocer con sencillez tanto la 'carga económica' que realmente supone para él el contrato celebrado, esto es, la onerosidad o sacrificio patrimonial realizada a cambio de la prestación económica que se quiere obtener, como la carga jurídica del mismo, es decir, la definición clara de su posición jurídica tanto en los presupuestos o elementos típicos que configuran el contrato celebrado, como en la asignación o distribución de los riesgos de la ejecución o desarrollo del mismo". Añadiendo que "en este segundo examen, la transparencia documental de la cláusula, suficiente a efectos de incorporación a un contrato suscrito entre profesionales y empresarios, es insuficiente para impedir el examen de su contenido y, en concreto, para impedir que se analice si se trata de condiciones abusivas. Es preciso que la información suministrada permita al consumidor percibir que se trata de una cláusula que define el objeto principal del contrato, que incide o puede incidir en el contenido de su obligación de pago y tener un conocimiento real y razonablemente completo de cómo juega o puede jugar en la economía del contrato"». La importancia de este segundo control de transparencia en relación con las cláusulas no negociadas individualmente relativas al objeto principal del contrato se pone de manifiesto en las conclusiones alcanzadas por el Alto Tribunal: «a) Que el cumplimiento de los requisitos de transparencia de la cláusula aisladamente considerada, exigidos por la LCGC para la incorporación a los contratos de condiciones generales, es insuficiente para eludir el 
control de abusividad de una cláusula no negociada individualmente, aunque describa o se refiera a la definición del objeto principal del contrato, si no es transparente. b) Que la transparencia de las cláusulas no negociadas, en contratos suscritos con consumidores, incluye el control de comprensibilidad real de su importancia en el desarrollo razonable del contrato». Como afirma la antes citada Sentencia del Tribunal Supremo de 8 de septiembre de 2014, «el control de transparencia, como proyección nuclear del principio de transparencia real en la contratación seriada y, por extensión, en el desarrollo general del control de inclusión, (artículo 5 de la Directiva 93/13, artículos 5.5 y 7.b de la LCGC y artículo 80.1 a TR- LGDCU) queda caracterizado como un control de legalidad en orden a comprobar, primordialmente, que la cláusula contractual predispuesta refiera directamente la comprensibilidad real, que no formal, de los aspectos básicos del contrato en el marco de la reglamentación predispuesta, de forma que el consumidor y usuario conozca y comprenda las consecuencias jurídicas que, de acuerdo con el producto o servicio ofertado, resulten a su cargo, tanto respecto de la onerosidad o sacrificio patrimonial que realmente supone para el consumidor el contrato celebrado, como de la posición jurídica que realmente asume en los aspectos básicos que se deriven del objeto y de la ejecución del contrato, STS de 26 de mayo de 2014 (núm. 86/2014)». Y añade esta Sentencia que «(...) el control de transparencia responde a un previo y especial deber contractual de transparencia del predisponente que debe quedar plasmado en la comprensibilidad real de los aspectos básicos del contrato que reglamenten las condiciones generales [...] el control de transparencia se proyecta de un modo objetivable sobre el cumplimiento por el predisponente de este especial deber de comprensibilidad real en el curso de la oferta comercial y de su correspondiente reglamentación seriada. Se entiende, de esta forma, que este control de legalidad o de idoneidad establecido a tal efecto, fuera del paradigma del contrato por negociación y, por tanto, del plano derivado de los vicios del consentimiento, no tenga por objeto el enjuiciamiento de la validez del consentimiento otorgado, ni el plano interpretativo del mismo, irrelevantes tanto para la validez y eficacia del fenómeno, en sí mismo considerado, como para la aplicación del referido control sino, en sentido diverso, la materialización o cumplimiento de este deber de transparencia en la propia reglamentación predispuesta; SSTJUE de 21 de febrero de 2013, C-427/11 y de 14 de marzo de 2013, C-415/11, así como STS de 26 de mayo de 2014 (núm. 86/2014)». La caracterización básica que define el control de transparencia, como ha puesto de manifiesto la doctrina y resulta especialmente de las expresadas STS de 9 de mayo de 2013 y 8 se septiembre de 2014, responde a la expansión conceptual del principio de buena fe, como presupuesto tanto del control de eficacia de las condiciones generales, como de fuente de creación de especiales deberes por parte del predisponente, que, por ejemplo, en este ámbito de las cláusulas limitativas de los tipos de interés se proyectarían en una adecuada diferenciación de las mismas a través de sus inclusión en una cláusula propia, o su indicación en párrafo separado y con letras en negrita, mayúsculas o subrayado, y la información sobre escenarios posibles o de la evolución histórica de los tipos de interés adoptados. A la luz de estos claros criterios jurisprudenciales se debe realizar la valoración del defecto opuesto en la calificación impugnada, pues, como se ha expuesto, la expresión manuscrita a que se refiere el artículo 6 de la Ley 1/2013, de 14 de mayo, está relacionada con los criterios de transparencia e información contractual fijados por el Tribunal Supremo en las citadas Sentencias. 5. Pues bien, es este control previo y doble de incorporación y transparencia el que se ha visto reforzado por el artículo 6 de la Ley 1/2013, de 14 de mayo, cuya interpretación se ha de hacer partiendo del contexto legal y jurisprudencial, nacional y comunitario, que se ha expuesto en el precedente fundamento, contexto que condiciona la validez de las cláusulas hipotecarias al cumplimiento de los requisitos legales tendentes a asegurar una compresibilidad real de las mismas por parte del prestatario. Es decir, frente a la opinión de quienes defienden una interpretación restrictiva del indicado artículo, debe prevalecer una interpretación extensiva pro-consumidor en coherencia con la finalidad legal de favorecer respectivamente la información, comprensibilidad y la protección de los usuarios de servicios financieros (vid. Resolución de 29 de septiembre de 2014). El control de inclusión o incorporación al contrato de las cláusulas de los contratos sobre servicios financieros que revistan caracteres de condición general de la contratación, viene regulado en la actualidad por la Orden EHA/2899/2011, de 28 de octubre, de transparencia y protección del cliente de servicios bancarios, que impone determinados deberes de información a las entidades prestamistas y al notario que autoriza la correspondiente escritura, que de forma sintética, comienzan por la entrega al solicitante de una guía del préstamo hipotecario (artículo 20), sigue con la Ficha de Información Precontractual (FIPRE) (artículo 21), continua luego con la Ficha de Información Personalizada (FIPER) que incluye las condiciones financieras (entre ellas, en su caso, tipo de interés variable y límites a la variación del tipo de interés) (artículos 22, 24 y 25) y con la oferta vinculante que incluye las mismas condiciones financieras (artículo 23), más el posible examen de la escritura pública por el prestatario durante los tres días anteriores al otorgamiento (artículo 30.2) y, por último, se formaliza el préstamo en escritura pública, estando obligado el notario a informar a las partes y a advertir, entre otras, sobre las circunstancias del interés variable, de las limitaciones del tipo de interés y, especialmente, si las limitaciones a la variación del tipo de interés no son semejantes al alza y a la baja (artículo 30.3). El cumplimiento de este proceso de contratación es considerado por el Alto Tribunal como suficiente para entender cumplido el control de incorporación, sin embargo, no considera el Tribunal Supremo en la citada sentencia de 9 de mayo de 2013 que la información que se facilita en los términos del proceso de negociación indicados cubra las exigencias del control de transparencia, ni las positivas de conocimiento real, completo y efectivo por el adherente, al tiempo de la celebración del contrato, de las consecuencias económicas y jurídicas de las cláusulas de los préstamos hipotecarios, ni las negativas de no ser ilegibles, ambiguas, oscuras e incomprensibles (artículo 7 de la Ley sobre condiciones generales de la contratación). En definitiva, las conclusiones que se extraen de estas Sentencias del Tribunal Supremo, en cuanto a lo que ahora nos interesa, se pueden sintetizar señalando que: a) los intereses del préstamo oneroso constituyen el precio que debe pagar el prestatario y, por tanto, si se pactan, son un elemento esencial del contrato, y el mismo carácter tendrán las cláusulas limitativas de los intereses en cuanto que son elementos configuradores de dicho precio e inescindibles del mismo; b) las cláusulas limitativas de la variabilidad de los intereses, aunque tengan el carácter de condición general de la contratación, al ser definitorias del objeto principal del contrato -el precio-, no admiten un control de abusividad, basado en el posible desequilibrio de las prestaciones, pero sí quedan sometidas al doble control de incorporación y transparencia; c) el cumplimiento de la regulación legal del proceso de concesión de los préstamos hipotecarios (entonces la Orden de 5 de mayo de 1994) satisface los requisitos exigidos por la Ley 
sobre condiciones generales de la contratación para la incorporación de las condiciones generales de la contratación a los contrato suscritos con consumidores; pero no supera el necesario control de transparencia que implica la existencia de una comprensibilidad real del prestatario acerca de la importancia de la cláusula suelo, y limitativas en general de la variabilidad del interés, en el desarrollo razonable del contrato, ya que no se resalta adecuadamente -en los modelos analizados- su transcendencia y efectos, y se insertan de forma conjunta con otras estipulaciones que las enmascaran, y d) las cláusulas limitativas de la variabilidad de los intereses son lícitas y, por tanto, no abusivas por sí mismas ya que corresponde al profesional fijar al interés al que presta el dinero, pero sí se considerarán abusivas y, por tanto, nulas, si falta el requisito de la transparencia. Por ello, para asegurar la existencia de dicha transparencia, el referido artículo 6 de la Ley 1/2013, de 14 de mayo, de medidas para reforzar la protección a los deudores hipotecarios, reestructuración de deuda y alquiler social, ha regulado, en el ámbito de los préstamos y créditos hipotecarios, un requisito especial: «la expresión manuscrita» del prestatario acerca de su real comprensión del riesgo que asume, para que se pueda entender cumplida la necesaria transparencia respecto de las cláusulas de mayor transcendencia y dificultad cognoscitiva contenidas en este tipo de contratos, como son las que limitan la variabilidad del tipo de interés, las que lo sujetan a un instrumento de cobertura del riesgo de tipo de interés, o las denominadas cláusulas multidivisa. Y este requisito, como ponen de manifiesto las Resoluciones de 12 de marzo, 8 y 27 de octubre y 10 de diciembre de 2015 y 15 de julio de 2016, es de carácter imperativo dada la literalidad del citado artículo 6 que utiliza la expresión «se exigirá que la escritura pública incluya, junto a la firma del cliente, una expresión manuscrita...», por lo que la alegación de que al no fijar dicha norma de manera expresa los efectos de su incumplimiento, la falta de la expresión manuscrita no debe impedir la inscripción de la escritura de préstamo hipotecario, no puede admitirse. Respecto de la no inscripción de la propia cláusula de limitación de la variabilidad del tipo de interés porque su nulidad derivaría de la declaración general que en tal sentido realiza el artículo 8.1 de la Ley sobre condiciones generales de la contratación en relación con las cláusulas predispuestas que contradigan una norma imperativa y el artículo 83 de la Ley General para la Defensa de los Consumidores y Usuarios en relación con las cláusulas abusivas, dado que la falta de la expresión manuscrita provoca la ausencia trasparencia de la estipulación y, en consecuencia, su abusividad en los términos señalados por el Tribunal Supremo. Y respecto de la escritura de préstamo hipotecario porque estas cláusulas de tipo suelo y similares configuran un objeto principal de los préstamos onerosos, como es el interés o precio, y, en consecuencia, la obligación de pago de intereses remuneratorios garantizada por la hipoteca, por lo que para la inscripción parcial de la escritura sin tales cláusulas, se precisa la solicitud expresa de los interesados (vid. artículos 19 bis y 322 de la Ley Hipotecaria y Resolución de 18 de febrero de 2014, entre otras). 6. Así planteados los términos del debate, la alegación por el notario recurrente de que la cláusula discutida que señala que «Debido a la naturaleza del contrato, en ningún caso se podrán generar intereses a favor del prestatario», no constituye una cláusula suelo del cero por ciento sino una cláusula aclaratoria de una condición esencial del contrato de préstamo que se firma (derivada del pacto de sistema francés de amortización), ya que aunque no existiera, éste no podría generar intereses negativos porque en tal caso la fórmula matemática del indicado sistemas de amortización lo impediría y se vería alterada su naturaleza jurídica y, por tanto, esta aclaración no puede provocar la exigencia de la constancia de la expresión manuscrita, tampoco puede admitirse. Ello es así porque a los efectos de la aplicación del artículo 6 de la Ley 1/2013 es irrelevante que la concurrencia de intereses negativos durante un determinado período del contrato, altere la naturaleza jurídica de éste convirtiéndole, por ejemplo, en un contrato de depósito retribuido; o que, por el contrario, al tratarse de un contrato de larga duración y constituir el interés, como ha puesto de manifiesto el Tribunal Supremo, el precio de préstamo, tal posibilidad sea únicamente una forma acordada por las partes de fijar el precio final, el cual gozará de cierta aleatoriedad (la fluctuación del interés) y vendrá constituido por el montante neto de los intereses devengados al término del contrato, montante que sí deberá ser siempre positivo. Es decir, el citado artículo 6 deberá aplicarse, tanto si se considera que la cláusula de variabilidad del interés no es suficiente para generar una obligación de pago por parte del prestamista (los intereses negativos), como si se entiende, en el segundo caso, que los intereses que finalmente pague el prestatario serán una consecuencia de la propia operatividad de la variabilidad de los mismos, la cual se asemeja, en cierta medida, a la de los instrumentos estructurados, cuya contratación asociada a un préstamo hipotecario, por otra parte y como se infiere del propio artículo 6, no altera la naturaleza jurídica del préstamo ni excluye la necesidad de la expresión manuscrita sino que la impone especialmente. El pago de intereses -los negativos- por parte del acreedor en favor del prestatario no transforma el préstamo convirtiéndolo en un depósito retribuido, como se alega por algún sector doctrinal, porque la causa jurídica de ambos contratos es distinta y tal pago carece de virtualidad para alterar la obligación del deudor de devolución del dinero recibido por cuotas en los plazos pactados, en una obligación de devolución íntegra a solicitud del depositante o prestamista (artículos 1766 y 1775 del Código Civil), y porque cuando el depositario tiene permiso para servirse del dinero depositado, el contrato pierde el concepto de depósito y se convierte en un préstamo (artículo 1768 del Código Civil). Igualmente irrelevante para la aplicación del citado artículo 6 de la Ley 1/2013 resulta la afirmación del notario recurrente de que la cláusula citada es la aclaración de una condición esencial del contrato derivada del sistema de amortización francés pactado, porque, en tal caso, igual que si se hubiere convenido el sistema alemán, americano o cualquier otro de amortización, el control del cumplimiento de los requisitos legales de transparencia respecto de las cláusulas del préstamo hipotecario derivadas de un acuerdo contractual, es decir, que no sean reproducción de disposiciones legales imperativas (artículo 1 de la Directiva 93/13), se hace más necesario. Lo que sí es posible interpretar es que con esta cláusula se quiere significar que existirán unos períodos del préstamo en los que el contrato devengará intereses y otros en los cuales no concurrirá tal devengo, posibilidad que se infiere del artículo 1740 del Código Civil, determinándose por dicha cláusula o por el conjunto con otras cuándo tiene lugar esta circunstancia. Pero, aunque este fuere el caso, y reconociendo que en dicha situación no nos encontraríamos propiamente ante una cláusula suelo, la propia complejidad de la situación que se genera (o del entendimiento del sistema de amortización francés), como ponen de manifiesto las distintas tesis explicativas acerca de su naturaleza y efectos, reconducen el tema al marco del control de transparencia o comprensibilidad por parte del deudor. Por tanto, si el prestamista, en ejercicio de su legítimo derecho, predispone una cláusula que limite o excluya la posibilidad de que devenguen intereses a favor del prestatario, aunque sea a efectos aclaratorios de 
Al admitir esta posibilidad, las entidades financieras están insertando cláusulas limitativas de intereses por debajo de cero, que el Centro Directivo entiende que deben ser tratadas con los mismos requisitos que las cláusulas suelo.

\section{Efectos ex tunc de la nulidad}

8. Admitido por tanto que las cláusulas suelo pueden ser nulas por abusivas si no han sido suficientemente explicadas al consumidor, tal como señala la sentencia del Tribunal Supremo de 9 de Mayo de 2013, el problema que se plantea es el de los efectos de la declaración de nulidad.

Es evidente que el primer efecto que se produce como consecuencia de la nulidad de la cláusula suelo es el de la necesidad de restitución de los intereses indebidamente devengados (ex. Artículo 1303 Código Civil) como consecuencia de la aplicación de la cláusula suelo, pero no determina la nulidad del préstamo en su conjunto. Dicho de otra forma, no es que deban restituirse todos los intereses devengados por el mero hecho de que se haya insertado una cláusula devenida abusiva por falta de transparencia, sino tan sólo los que se hayan pagado por exceso con relación a los tipos efectivos de interés que sin la cláusulas hubieran sido aplicados indebidamente desde que la bajada de los tipos de interés haya alcanzado el mínimo fijado en las condiciones generales del contrato.

9. En efecto el Tribunal Supremo en su Sentencia n. ${ }^{0}$ 139/2015, de 25 de marzo de 2015 declaró que los contratos de préstamo hipotecario afectados por la cláusula suelo afectada por nulidad, podían

los efectos típicos del contrato o del significado de una de las cláusulas pactadas, su incorporación al contrato de préstamo hipotecario exigirá, por disposición imperativa y como canon de transparencia, la aportación de la repetida expresión manuscrita. Además, la sentencia del Tribunal Supremo de 9 de mayo de 2013 señala, como ya se ha indicado anteriormente, que el control de transparencia tiene por objeto «que el adherente conozca o pueda conocer con sencillez tanto la "carga económica" que realmente supone para él el contrato celebrado, esto es, la onerosidad o sacrificio patrimonial realizada a cambio de la prestación económica que se quiere obtener, como la carga jurídica del mismo, es decir, la definición clara de su posición jurídica "tanto en los presupuestos o elementos típicos" que configuran el contrato celebrado, "como en la asignación o distribución de los riesgos" de la ejecución o desarrollo del mismo», es decir, que tal control de transparencia y el cumplimiento de sus requisitos legales, cuya finalidad es lograr la certeza de que el prestatario ha comprendido las consecuencia económicas y jurídicas del contrato que firma y de sus cláusulas asociadas, operan tanto si la limitación a la variabilidad de los intereses a la baja resulta de un pacto expreso del tipo cláusula suelo, como si la misma deriva, en determinados supuestos, de la propia naturaleza o tipicidad del contrato de préstamo o de un pacto de exclusión de devengo de intereses (directa o como consecuencia del sistema de amortización elegido), sin perjuicio de que, en tales casos, la denominada expresión manuscrita pueda ser objeto de la correspondiente adaptación. La afirmación acerca de que la cláusula debatida no constituye una auténtica cláusula suelo y que, por tanto, la literalidad del artículo 6 excluirá el requisito a que se viene haciendo referencia, tampoco merece una consideración favorable porque, aun siendo correcto que tal estipulación no constituye propiamente una cláusula suelo, independientemente que la aplicación del principio general antes enunciado de la interpretación pro consumidor de las normas que regulan las condiciones generales de la contratación y la protección de los consumidores conduciría a su asimilación; lo cierto es que dicho artículo y sus concordantes no tienen como ámbito de aplicación las cláusulas suelo estrictamente consideradas sino todas aquellas, del tipo que sean, que limiten de alguna forma la variabilidad de los intereses, entre las cuales se encuadra la que es objeto de este expediente que excluye el devengo de intereses cuando los mismos puedan ser negativos. Así, el repetido artículo 6 de la Ley 1/2013 dispone como ámbito de su aplicación las escrituras públicas en que se estipulen «limitaciones a la variabilidad del tipo de interés», es decir, todas ellas, añadiendo a título de ejemplo «del tipo de las cláusulas suelo y techo»; y el artículo 25 de la Ley sobre condiciones generales de la contratación, en los mismos términos, impone la exigencia de una información adicional por parte del prestamista en el caso de préstamos en que se hubieran establecido «límites a la variación del tipo de interés», añadiendo «como cláusulas suelo o techo», pero no sólo en estos casos estrictamente considerados. Por último, en el mismo sentido, el artículo 30, número 3, letra b), circunstancia 3ª de la Orden EHA 2899/2011 regula la información expresa y especial que debe dar el notario autorizante en las escrituras de préstamo hipotecario en que «se hubieran establecido límites a la variación del tipo de interés, como cláusulas suelo o techo». Es cierto, como ya señalaron las Resoluciones de 12 de marzo, 8 y 27 de octubre y 10 de diciembre de 2015 y 15 de julio de 2016, que de «lege ferenda» el control de transparencia debería entenderse cumplido con la manifestación expresa por parte del notario de haberse cumplido con las exigencias informativas y clarificadoras impuestas por la regulación sectorial, de que la cláusula es clara y comprensible y de que el consumidor ha podido evaluar directamente, basándose en criterios y explicaciones comprensibles, las consecuencias jurídicas y económicas a su cargo derivadas de las cláusulas contractuales predispuestas; añadiendo, si se estima conveniente, que expresamente éste ha manifestado al notario la compresión de las mismas en los supuestos especiales respecto a los que ahora se exige la expresión manuscrita. Pero como se ha expuesto anteriormente ésta no es la situación legislativa y jurisprudencial vigente en el momento actual. 
subsistir, si bien limitó la retroactividad de los efectos de la declaración de nulidad de las cláusulas suelo a aquéllas cláusulas suelo que se hubieran aplicado con posterioridad a la Sentencia del Tribunal Supremo de 9 de Mayo de 2013.

A este respecto, tras recordar que, a tenor de la jurisprudencia del Tribunal de Justicia en materia de declaración de nulidad de las cláusulas abusivas, debía considerarse que las cláusulas en cuestión no habían surtido efecto alguno, el Tribunal Supremo declaró que, no obstante la regla general de eficacia retroactiva de las declaraciones de nulidad, esta eficacia no podía ser impermeable a los principios generales del Derecho y, entre ellos, de forma destacada, al principio de seguridad jurídica. Para ello el Tribunal Supremo se basó en que las cláusulas suelo eran lícitas en cuanto tales; que respondían a razones objetivas; que no se trataba de cláusulas inusuales o extravagantes; que su utilización había sido tolerada largo tiempo por el mercado de préstamos inmobiliarios; que la nulidad de las mismas derivaba de una falta de transparencia debido a la insuficiencia de la información a los prestatarios; que las entidades crediticias habían observado las exigencias reglamentarias de información; que la finalidad de la fijación del tope mínimo respondía a la necesidad de mantener un rendimiento mínimo de los referidos préstamos hipotecarios que permitiera a las entidades bancarias resarcirse de los costes de producción y mantenimiento de estas financiaciones; que las cláusulas suelo se calculaban para que no implicasen cambios significativos en las cuotas iniciales a pagar, tenidas en cuenta por los prestatarios en el momento de decidir sus comportamientos económicos; que la legislación española permitía la sustitución del acreedor, y que la retroactividad de la declaración de nulidad de las cláusulas en cuestión generaría el riesgo de trastornos económicos graves.

En este extremo -el de la irretroactividad- el que el TJUE casa el criterio del TS español. El Tribunal Supremo, con fundamento en el principio de seguridad jurídica, limitó la eficacia temporal de su sentencia y dispuso que ésta sólo surtiría efectos a partir de la fecha de su publicación, declarando que la nulidad de las cláusulas suelo controvertidas no afectaría a las situaciones definitivamente decididas por resoluciones judiciales con fuerza de cosa juzgada ni a los pagos ya efectuados antes del 9 de mayo de 2013, de manera que tan sólo deberían restituirse las cantidades indebidamente pagadas, sobre la base de tales cláusulas, con posterioridad a aquella fecha (eficacia ex nunc).

Frente a ello la sentencia del TJUE ahora comentada, de fecha 21 de diciembre de 2016 sostiene la eficacia ex tunc o retroactiva de la nulidad. Y considera que no debió aplicarse el mismo criterio de limitación de los efectos por razón de seguridad jurídica que el propio TJUE había sostenido para las acciones colectivas, pues se trataba de una acción de nulidad individual. Y aunque admite que el tema de la prescripción es un tema de Derecho procesal interno, considera que no puede interpretarse contraviniendo el principio de equivalencia de la Unión Europea ${ }^{10}$.

\footnotetext{
${ }^{10} \mathrm{Si}$ bien es verdad -dice la sentencia- que corresponde a los Estados miembros, mediante sus respectivos Derechos nacionales, precisar las condiciones con arreglo a las cuales se declare el carácter abusivo de una cláusula contenida en un contrato y se materialicen los efectos jurídicos concretos de tal declaración, no es menos cierto que la declaración del carácter abusivo de la cláusula debe permitir que se restablezca la situación de hecho y de Derecho en la que se encontraría el consumidor de no haber existido tal cláusula abusiva, concretamente mediante la constitución de un derecho a la restitución de las ventajas obtenidas indebidamente por el profesional en detrimento del consumidor en virtud de la cláusula abusiva. En el caso de autos, en la sentencia de 9 de mayo de 2013, a la que hacen referencia los órganos jurisdiccionales remitentes, el Tribunal Supremo determinó que la declaración del carácter abusivo de las cláusulas suelo controvertidas no afectaba a las situaciones definitivamente decididas por resoluciones judiciales con fuerza de cosa juzgada ni a los pagos ya efectuados antes de la fecha en que se dictó la propia sentencia y que, por consiguiente, en virtud del principio de seguridad jurídica, los efectos derivados de tal declaración —especialmente el derecho del consumidor a la restitución — quedaban limitados a las cantidades indebidamente pagadas a partir de aquella fecha. A este respecto, es verdad que el Tribunal de Justicia ya ha reconocido que la protección del consumidor no es absoluta. En este sentido ha declarado, en particular, que el Derecho de la Unión no obliga a un tribunal nacional a dejar de aplicar las normas procesales internas que confieren fuerza de cosa juzgada a una resolución, aunque ello permitiera subsanar una infracción de una disposición, cualquiera que sea su naturaleza, contenida en la Directiva 93/13 (véase, en este sentido, la STJUE de 6 de octubre de 2009, Asturcom Telecomunicaciones, C-40/08, EU:C:2009:615, apartado 37). De ello se deduce que el Tribunal Supremo podía declarar legítimamente, en la sentencia de 9 de mayo de 2013, que esta última no afectaba a las situaciones definitivamente decididas por resoluciones judiciales anteriores con fuerza de cosa juzgada. Del mismo modo, el Tribunal de Justicia ya ha declarado que la fijación de plazos razonables de carácter preclusivo para recurrir, en interés de la seguridad jurídica, es compatible con el Derecho de la Unión (STJUE de 6 octubre de 2009, Asturcom Telecomunicaciones, C-40/08, EU:C:2009:615, apartado 41). No obstante, es preciso distinguir la aplicación de una regla procesal - como es un plazo razonable de prescripción— de la limitación en el tiempo de los efectos de la interpretación de una norma
} 
En efecto, en la sentencia n. ${ }^{\circ}$ 139/2015, de 25 de marzo de 2015 el Tribunal Supremo confirmó la limitación de los efectos retroactivos de la declaración de nulidad de una cláusula suelo en el marco de la demanda individual de un consumidor que reclamaba la restitución de las cantidades indebidamente pagadas sobre la base de una cláusula de este tipo. Al proceder de esta manera, el Tribunal Supremo hizo extensiva a las acciones individuales de cesación y de reparación la solución adoptada anteriormente por la sentencia de 9 de mayo de 2013 en lo relativo a las acciones colectivas de cesación. Así pues, en el asunto que dio lugar a la sentencia de 25 de marzo de 2015, la obligación de restitución se limitó exclusivamente a las cantidades indebidamente pagadas con posterioridad al pronunciamiento de la sentencia de 9 de mayo de 2013.

10. Y esto es lo que la Sentencia del TJUE de 21 de Diciembre de 2016 no acepta, pese a que en principio era la posición sostenida por el Abogado General ante el TJUE ${ }^{11}$. Y da la razón al voto particular del Magistrado Javier Orduña que en la sentencia de 25 de Marzo de 2015 había sostenido que en el caso de ejercicio de las acciones individuales, los criterios que resultan aplicables no dan otra alternativa posible que no sea la determinada del efecto devolutivo de las cantidades ya pagadas con carácter "ex tunc", esto es, desde el momento de la perfección del contrato predispuesto.

\section{Prescripción de la acción}

11. Ahora bien, queda por determinar cuándo prescribe la acción de nulidad. Si entendemos que la cláusula suelo es nula cuando ha sido incluida en condiciones generales de la contratación y se

del Derecho de la Unión (véase, en este sentido, la STJUE de 15 de abril de 2010, Barth, C-542/08, EU:C:2010:193, apartado 30 y jurisprudencia citada). A este respecto, procede recordar que, habida cuenta de la exigencia fundamental de una aplicación uniforme y general del Derecho de la Unión, el Tribunal de Justicia es el único que puede decidir acerca de las limitaciones en el tiempo que hayan de aplicarse a la interpretación que él mismo haya hecho de una norma del Derecho de la Unión (véase, en este sentido, la STJUE 2 de febrero de 1988, Barra y otros, 309/85, EU:C:1988:42, apartado 13). Así pues, las condiciones estipuladas por los Derechos nacionales, a las que se refiere el artículo 6, apartado 1, de la Directiva 93/13, no podrán afectar al contenido sustancial del derecho a no estar vinculado por una cláusula considerada abusiva, derecho que la citada disposición, tal como ha sido interpretada por la jurisprudencia del Tribunal de Justicia recordada en los apartados 54 a 61 de la presente sentencia, atribuye a los consumidores. Pues bien, la limitación en el tiempo de los efectos jurídicos derivados de la declaración de nulidad de las cláusulas suelo, que el Tribunal Supremo acordó en la sentencia de 9 de mayo de 2013, equivale a privar con carácter general a todo consumidor que haya celebrado antes de aquella fecha un contrato de préstamo hipotecario que contenga una cláusula de ese tipo del derecho a obtener la restitución íntegra de las cantidades que haya abonado indebidamente a la entidad bancaria sobre la base de la cláusula suelo durante el período anterior al 9 de mayo de 2013.

11 Según las conclusiones elevadas el 13 de julio de 2016 ante el TJUE por el abogado general Paolo Mengozzi en los asuntos acumulados C-154/15, C-307/15 y C-308/15 la retroacción de los efectos de la nulidad de tales cláusulas en los contratos de préstamo hipotecario en España habría de haberse limitado a la fecha de publicación de la primera sentencia del Tribunal Supremo, el 9 de mayo de 2013, pues a su entender la Directiva 93/13/CEE del Consejo, de 5 de abril de 1993 no tiene por objeto la armonización de las sanciones aplicables en caso de que se aprecie el carácter abusivo de una cláusula contractual, y por lo tanto, no exige a los Estados miembros que establezcan la nulidad retroactiva de tal cláusula. Asimismo, continua en su informe, la Directiva no determina las condiciones en las que un órgano jurisdiccional nacional puede limitar los efectos de las resoluciones por las que se califica como abusiva una cláusula contractual. Entiende que corresponde al ordenamiento jurídico interno precisar esas condiciones, siempre desde el respeto de los principios de equivalencia y de efectividad del derecho de la Unión. Respecto al principio de equivalencia (que exige que una norma nacional se aplique indistintamente a los recursos basados en la vulneración del Derecho de la Unión y a los que se fundamentan en el incumplimiento del Derecho interno y que tengan un objeto y una causa semejantes) el Abogado General subraya que el Tribunal Supremo no limita los efectos en el tiempo de sus resoluciones únicamente a los litigios relativos al Derecho de la Unión. Al contrario, consta que este órgano jurisdiccional ya ha recurrido a tal posibilidad en controversias puramente internas. En cuanto al principio de efectividad (que exige que una norma procesal nacional no haga imposible o excesivamente difícil la aplicación del Derecho de la Unión), entendía que, dado que constituyen una sanción con efecto disuasorio para los profesionales, la prohibición de utilizar las cláusulas «suelo» a partir del 9 de mayo de 2013 y la obligación de devolver las cantidades indebidamente percibidas a partir de esa fecha contribuyen a la realización de los objetivos perseguidos por la Directiva. Según el Abogado General, en el momento en que se pronuncia acerca de los efectos en el tiempo de su resolución, un órgano jurisdiccional supremo puede ponderar la protección de los consumidores con las repercusiones macroeconómicas asociadas a la amplitud con que se utilizaron las cláusulas «suelo». En este contexto, considera que, a título de excepción, las mencionadas repercusiones pueden justificar la limitación en el tiempo de los efectos de la nulidad de una cláusula abusiva, sin que se rompa el equilibrio en la relación existente entre el consumidor y el profesional. Según el informe del Abogado General el Tribunal de Justicia debía haber declarado que la limitación en el tiempo de los efectos de la nulidad de las cláusulas «suelo», incluidas en los contratos de préstamo hipotecario en España, es compatible con la Directiva. 
ha incumplido el doble control de incorporación y transparencia, y que es retroactiva, las entidades financieras deberán devolver todo lo que hubieran cobrado indebidamente aplicando la cláusula, por tanto desde que la evolución a la baja de los tipos de interés variable pactados hubiera provocado la aplicación de aquélla.

El Código Civil determina que el plazo para el ejercicio de la acción de nulidad en caso de error es de cuatro años, computados desde la consumación del contrato (cfr. Artículo 1301 C.C.). Pudiera pensarse que el contrato se ha consumado desde la formalización del contrato y la entrega del dinero prestado (el contrato de préstamo es un contrato real que se perfecciona por la entrega), por lo que muchos consumidores habrían perdido la posibilidad de ejercitar la acción individual de nulidad contractual. Sin embargo el Tribunal Supremo sostiene que cuando se trata de la comercialización de productos financieros complejos, el cómputo a efectos de caducidad de la acción de nulidad no comienza el día en que se perfeccionó el contrato de aportaciones financieras subordinadas, sino cuando el cliente tuvo conocimiento de la existencia de la circunstancia que provocó el error vicio, dado que la entidad bancaria está obligada a suministrar una información clara y comprensible al cliente que le permitiera conocer las características del producto y sus riesgos.

Así la Sentencia $n^{\circ} 718 / 2016$ de TS, Sala $1^{\text {a }}$, tras referirse a la existencia de diferencias en la interpretación del art. $1301 \mathrm{CC}$, en relación con el comienzo del cómputo del plazo para el ejercicio de la acción de nulidad basada en el error vicio del consentimiento, establece que esta cuestión, ciertamente controvertida, ha sido resuelta en el sentido de que en las relaciones contractuales complejas como son con frecuencia las derivadas de contratos bancarios, financieros o de inversión, la consumación del contrato, a efectos de determinar el momento inicial del plazo de ejercicio de la acción de anulación del contrato por error o dolo, no puede quedar fijada antes de que el cliente haya podido tener conocimiento de la existencia de dicho error o dolo ${ }^{12}$.

12. Desde otra perspectiva hay que destacar como la jurisprudencia del TJUE ha significado un claro respaldo a la posibilidad de rechazo de la autorización por los notarios y a la posibilidad de calificación por parte de los registradores de la propiedad -como autoridad pública que son, incluidos por tanto en el concepto a que se refiere el artículo 3 de la Directiva 93/13/CE sobre nulidad de cláusulas abusivas en los contratos con consumidores- de las cláusulas de los préstamos hipotecarios que puedan ser nulas por abusivas. No sólo son los jueces los que pueden apreciar cláusulas abusivas, sino cualquier autoridad pública, sin necesidad de pronunciamiento judicial previo, pueden rechazar cláusulas abusivas

12 Fue en la sentencia de Pleno 769/2014, de 12 de enero de 2015, en la que ya el TS se pronunció sobre el comienzo del cómputo del plazo para el ejercicio de la acción de anulación por error vicio, previsto en el art. $1301 \mathrm{CC}$. Y este criterio ha sido reiterado por resoluciones posteriores, a partir de la sentencia 376/2015, de 7 de julio, por lo que puede hablarse de jurisprudencia en el sentido del art. 1.6 CC. De acuerdo con lo dispuesto en el art. 1301 del Código Civil, «[1]a acción de nulidad sólo durará cuatro años. Este tiempo empezará a correr: [...] En los [casos] de error, o dolo, o falsedad de la causa, desde la consumación del contrato [...] ». En aquella sentencia 769/2014, de 12 de enero de 2015, hacíamos una interpretación del 1301 $\mathrm{CC}$ de acuerdo con la realidad del tiempo en que debe ser ahora aplicado, en el siguiente sentido: al interpretar hoy el art. 1301 $\mathrm{CC}$ en relación a las acciones que persiguen la anulación de un contrato bancario o de inversión por concurrencia de vicio del consentimiento, no puede obviarse el criterio interpretativo relativo a " la realidad social del tiempo en que [las normas] han de ser aplicadas atendiendo fundamentalmente al espíritu y finalidad de aquéllas “, tal como establece el art. 3 CC .(...) En la fecha en que el art. $1301 \mathrm{CC}$ fue redactado, la escasa complejidad que, por lo general, caracterizaba los contratos permitía que el contratante aquejado del vicio del consentimiento, con un mínimo de diligencia, pudiera conocer el error padecido en un momento más temprano del desarrollo de la relación contractual. Pero en el espíritu y la finalidad de la norma se encontraba el cumplimiento del tradicional requisito de la "actio nata", conforme al cual el cómputo del plazo de ejercicio de la acción, salvo expresa disposición que establezca lo contrario, no puede empezar a computarse al menos hasta que se tiene o puede tenerse cabal y completo conocimiento de la causa que justifica el ejercicio de la acción. Tal principio se halla recogido actualmente en los principios de Derecho europeo de los contratos (art. 4:113). »En definitiva, no puede privarse de la acción a quien no ha podido ejercitarla por causa que no le es imputable, como es el desconocimiento de los elementos determinantes de la existencia del error en el consentimiento. »Por ello, en relaciones contractuales complejas como son con frecuencia las derivadas de contratos bancarios, financieros o de inversión, la consumación del contrato, a efectos de determinar el momento inicial del plazo de ejercicio de la acción de anulación del contrato por error o dolo, no puede quedar fijada antes de que el cliente haya podido tener conocimiento de la existencia de dicho error o dolo. El día inicial del plazo de ejercicio de la acción será, por tanto, el de suspensión de las liquidaciones de beneficios o de devengo de intereses, el de aplicación de medidas de gestión de instrumentos híbridos acordadas por el FROB, o, en general, otro evento similar que permita la comprensión real de las características y riesgos del producto complejo adquirido por medio de un consentimiento viciado por el error. 
en los contratos con consumidores. Incluso en un monitorio, el juez puede rechazar "ad limine litis", esto es, aunque todavía no haya oposición por parte del deudor, las cláusulas nulas por abusivas.

El artículo 12 de la Ley Hipotecaria ya autorizaba a los registradores de la propiedad para rechazar las cláusulas financieras contrarias a norma imperativa o prohibitiva. Y el artículo 84 del Texto Refundido de la Ley de Defensa de los Consumidores y Usuarios establece que los Notarios y los Registradores de la Propiedad y Mercantiles, en el ejercicio profesional de sus respectivas funciones públicas, no autorizarán ni inscribirán aquellos contratos o negocios jurídicos en los que se pretenda la inclusión de cláusulas declaradas nulas por abusivas en sentencia inscrita en el Registro de Condiciones Generales de la Contratación ${ }^{13}$.

Según esta posición -jurisprudencial y del Centro Directivo de notarios y registradores- más reciente y acertada podemos afirmar que los notarios y registradores deben rechazar aquéllas cláusulas financieras -incluidas las de vencimiento anticipado- siempre que su nulidad hubiera sido declarada mediante resolución judicial firme, pero también aquéllas cuyo carácter abusivo pueda ser apreciado sin necesidad de realizar ningún tipo de valoración de las circunstancias concurrentes en el caso concreto. Dicho de otro modo, el control sobre cláusulas abusivas debe extenderse a las que estén afectadas de una causa directa de nulidad apreciable objetivamente porque así resulte claramente de una norma que lo exprese sin poder entrar en conceptos jurídicos indeterminados o cuando así resulte de una sentencia judicial firme. Las citadas resoluciones, basándose en el Derecho comunitario, interpretan por tanto que no es necesario que la sentencia esté inscrita en el Registro de Condiciones Generales de la Contratación, basta con que exista un pronunciamiento judicial firme (como así ha ocurrido por ejemplo, en las cláusulas suelo) ${ }^{14}$. La posición de la DGRN ha obtenido un claro respaldo por la sentencia del Tribunal

${ }^{13}$ Sobre la imposibilidad de que la calificación registral se extendiera a todo tipo de condiciones generales abusivas, se había pronunciado la Dirección General de los Registros y del Notariado en resolución de 19 de Abril de 2006 y otras posteriores entre las que podemos destacar la Resolución de 24 de Julio de 2008. Esta última limitó exageradamente el papel de notarios y registradores en el control preventivo de las cláusulas abusivas y entendió que tras la Ley 41/2007 que reformó el artículo 12 de la Ley Hipotecaria, la inscripción en el Registro debería ser una transcripción de las cláusulas financieras en los mismos términos que resultaran del título, sin poder rechazar ninguna cláusula por abusiva. En contra de este criterio, la Sentencia de 1 de Abril de 2011 dictada por la Audiencia Provincial de Tarragona -en juicio verbal interpuesto contra la citada resolución-, procede a su anulación. Esta sentencia se basa en la doctrina jurisprudencial del Tribunal Supremo (en su Sentencia de 16 de Diciembre de 2009) y en la posición más reciente y adecuada de la propia Dirección General de los Registros y del Notariado (entre ellas resoluciones de 1 de Octubre de 2010, 4 de Noviembre de 2010, 21 de Diciembre de 2010 y 11 de Enero de 2011).

14 La propia Ley ya nos da algunos ejemplos de cláusulas abusivas, como las contenidas en el artículo 89 del TRLDCU aprobado por RDL 1/2007, de 16 de Noviembre. Interesa destacar en el ámbito registral o inmobiliario, como en todo caso tienen la consideración de cláusulas abusivas la imposición al consumidor de los gastos de documentación y tramitación que por ley corresponda al empresario. En particular, en la compraventa de viviendas:

a) La estipulación de que el consumidor ha de cargar con los gastos derivados de la preparación de la titulación que por su naturaleza correspondan al empresario (obra nueva, propiedad horizontal, hipotecas para financiar su construcción o su división y cancelación).

b) La estipulación que obligue al consumidor a subrogarse en la hipoteca del empresario o imponga penalizaciones en los supuestos de no subrogación.

c) La estipulación que imponga al consumidor el pago de tributos en los que el sujeto pasivo es el empresario -como es el caso del Impuesto sobre el Incremento de Valor de los Terrenos de Naturaleza Urbana (plusvalía)- que corresponde al vendedor.

d) La estipulación que imponga al consumidor los gastos derivados del establecimiento de los accesos a los suministros generales de la vivienda, cuando ésta deba ser entregada en condiciones de habitabilidad.

Pero además de las señaladas expresamente por la ley, en base a pronunciamientos judiciales y a la doctrina de la Dirección General de los Registros y del Notariado, podemos señalar como ejemplos de cláusulas que no deben incorporarse al título ni inscribirse en el Registro las siguientes:

a) vencimientos anticipados por cualquier embargo o disminución de solvencia del deudor en las que no se prevea la posibilidad de que el deudor preste nuevas garantías;

b) vencimiento anticipado por arrendamientos posteriores sujetos a purga, pues no perjudican a la hipoteca;

c) prohibición o limitación de la facultad de enajenar la finca, salvo que se tratara de hipoteca inversa en que dicho pacto es admisible según ley 41/2007;

d) renuncia del deudor a ser notificado de la cesión del crédito, considerándose derogado el artículo 242 del Reglamento Hipotecario que lo permitía;

e) vencimientos anticipados del préstamo hipotecario por incumplimiento de obligaciones accesorias del mismo;

f) cláusulas de comisión de cancelación o subrogatorias contrarias a los máximos legales;

g) cláusulas denominadas "suelo" donde se fija un tipo de interés mínimo pero no un tope máximo de evolución -cláusula "techo"-. La STS. de 9 de mayo de 2013 declara la nulidad de las cláusulas suelo contenidas en las condiciones generales 
Supremo (Sala de lo Civil), de 13 de septiembre de 2013, que señala que los registradores denegarán la inscripción de las escrituras de préstamos o crédito hipotecario cuando no cumplan la legalidad vigente. Se apoya en la legislación de la UE, en la Ley 2/2009, de 31 de marzo, y en los artículos 552 y 695 de la LEC, en cuanto regulan el tratamiento de las cláusulas abusivas en los procedimientos de ejecución, debiendo negar su colaboración con títulos jurídicos que sean evidentemente nulos ${ }^{15}$.

13. No obstante, debería avanzarse mucho más en el control de transparencia notarial y en la calificación registral de cláusulas abusivas. En particular debería hacerse obligatoria la puesta a disposición de los clientes, con varios días de anterioridad, la oferta precontractual, configurando como un derecho indisponible e irrenunciable del deudor de la posibilidad de conocer ésta. Asimismo, debería aprovecharse la transposición de la Directiva 2014/17/UE, sobre los contratos de crédito celebrados con los consumidores para bienes inmuebles de uso residencial, para incrementar la obligación de transparencia de las cláusulas financieras en los préstamos y créditos hipotecario recogida hasta ahora en la Orden ministerial EHA 2899/2011 de 28 de octubre de "transparencia y protección del cliente de servicios bancarios.

\section{EI mecanismo especial de arreglo de diferencias}

14. Finalmente terminaremos señalando como en el momento de redactarse estas líneas se ha aprobado el Real Decreto Ley 1/2017 de 20 de enero con la idea de facilitar la devolución por parte de las entidades financieras a los consumidores de las cantidades indebidamente cobradas por la aplicación de cláusulas suelo no transparentes. Se establece un procedimiento voluntario previo a la interposición de la demanda de nulidad que evite la sobrecarga de trabajo por los tribunales y facilite la devolución o en su caso novación del contrato de préstamo, fomentando medidas alternativas como es la devolución por la entidad financiera de los intereses excedidos, si es que se acepta por la entidad financiera la falta de transparencia de la cláusula, o bien la reducción de la carga financiera en los vencimientos posteriores del préstamo.

Las entidades de crédito deberán implantar un sistema de reclamación previa a la interposición de demandas judiciales, que tendrá carácter voluntario para el consumidor y cuyo objeto será atender a las peticiones que éstos formulen en el ámbito de este real decreto-ley. Las entidades de crédito deberán garantizar que ese sistema de reclamación es conocido por todos los consumidores que tuvieran incluidas cláusula suelo en su préstamo hipotecario.

Recibida la reclamación, la entidad de crédito deberá efectuar un cálculo de la cantidad a devolver y remitirle una comunicación al consumidor desglosando dicho cálculo; en ese desglose la entidad de crédito deberá incluir necesariamente las cantidades que correspondan en concepto de intereses. En el caso en que la entidad considere que la devolución no es procedente, comunicará las razones en que se motiva su decisión, en cuyo caso se dará por concluido el procedimiento extrajudicial. El consumidor deberá manifestar si está de acuerdo con el cálculo. Si lo estuviera, la entidad de crédito acordará con el consumidor la devolución del efectivo.

de los contratos suscritos con consumidores que no lleven aparejada una proporcional cláusula techo y en las que no se haya informado suficientemente de sus riesgos, aunque declara la subsistencia de los contratos de préstamo hipotecario en vigor, sin que haya lugar a la retroactividad de esta sentencia, que no afectará a las situaciones definitivamente decididas por resoluciones judiciales con fuerza de cosa juzgada ni los pagos ya efectuados en la fecha de publicación de dicha sentencia.

Por el contrario, sí que serían admisibles las siguientes:

a) el pacto de extensión de la hipoteca a las costas de la ejecución;

b) el pacto de liquidación unilateral por la entidad financiera (que no ha sido rechazado por la STJUE de 14 de Marzo de 2013;

c) pacto de compensación de la deuda con otros créditos vencidos del mismo deudor con la misma entidad salvo que deriven de créditos indistintos con varios titulares;

d) vencimiento anticipado del préstamo hipotecario por impago de tres cuotas de principal o intereses, tal como ha clarificado la Ley 1/2013 (por lo tanto no serían válidos los pactos de vencimiento anticipado por impago de una sola cuota).

e) vencimiento anticipado por arrendamiento de la vivienda hipotecada que no esté sujeto a purga conforme al artículo 13 de la LAU, puesto que tales arrendamientos sí perjudican al acreedor hipotecario, pues tendrá que subrogarse en ellos.

15 En el mismo sentido R 24 de octubre 2014. 
El plazo máximo para que el consumidor y la entidad lleguen a un acuerdo y se ponga a disposición del primero la cantidad a devolver será de tres meses a contar desde la presentación de la reclamación. A efectos de que el consumidor pueda adoptar las medidas que estime oportunas, se entenderá que el procedimiento extrajudicial ha concluido sin acuerdo:

a) Si la entidad de crédito rechaza expresamente la solicitud del consumidor.

b) Si finaliza el plazo de tres meses sin comunicación alguna por parte de la entidad de crédito al consumidor reclamante.

c) Si el consumidor no está de acuerdo con el cálculo de la cantidad a devolver efectuado por la entidad de crédito o rechaza la cantidad ofrecida.

d) Si transcurrido el plazo de tres meses no se ha puesto a disposición del consumidor de modo efectivo la cantidad ofrecida.

Si se interpusiera demanda con anterioridad a la finalización del procedimiento y con el mismo objeto que la reclamación de este artículo, cuando se tenga constancia, se producirá la suspensión del proceso hasta que se resuelva la reclamación previa.

Para fomentar el procedimiento se establece un régimen específico de pago de costas, de manera que solamente si el consumidor rechazase el cálculo de la cantidad a devolver o declinase, por cualquier motivo, la devolución del efectivo e interpusiera posteriormente demanda judicial en la que obtuviese una sentencia más favorable que la oferta recibida de dicha entidad, se impondrá la condena en costas a esta.

Si el consumidor interpusiere una demanda frente a una entidad de crédito sin haber acudido al procedimiento extrajudicial del artículo 3, regirán las siguientes reglas:

a) En caso de allanamiento de la entidad de crédito antes de la contestación a la demanda, se considerará que no concurre mala fe procesal, a efectos de lo previsto en el artículo 395.1 segundo párrafo, de la Ley 1/2000, de 7 de enero, de Enjuiciamiento Civil.

b) En el caso de allanamiento parcial de la entidad de crédito antes de la contestación a la demanda, siempre que consigne la cantidad a cuyo abono se comprometa, solo se le podrá imponer la condena en costas si el consumidor obtuviera una sentencia cuyo resultado económico fuera más favorable que la cantidad consignada. 